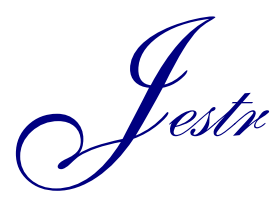

Journal of Engineering Science and Technology Review 10 (1) (2017) 18-23

Research Article

\title{
Mapping Seagrass Condition Using Google Earth Imagery
}

\author{
Muhammad Anshar Amran \\ Department of Marine Sciences, Hasanuddin University, Indonesia
}

Received 8 January 2017; Accepted 1 March 2017

\begin{abstract}
In order to manage seagrass ecosystems, detailed information on seagrass condition is needed. Remote sensing could be used to obtain information about seagrass condition. The high resolution images in Google Earth provide methodological development opportunities for seagrass condition mapping. This study aimed to assess the reliability of Google Earth imagery as a direct source of data for mapping seagrass condition. This study combined image processing and field survey. The image downloaded from Google Earth was a picture file in JPEG format which came from a GeoEye1 image. Image classification was done using the maximum likelihood method to obtain a map indicating seafloor typology. The resulting classes were seagrass beds, live coral, sand and dead coral, and deep sea. The seagrass class was further subdivided to represent conditions based on seagrass percentage cover. Classification accuracy was assessed using an error matrix to calculate overall accuracy and the Kappa Coefficient. Such a mapping method need not be expensive because Google Earth imagery can be downloaded for free.The results of this study showed that Google Earth imagery can be a reliable direct source of seagrass condition mapping data with good accuracy. The resulting map can provide detailed information when it comes from a high-resolution image.
\end{abstract}

Keywords: seagrass condition, percentage cover, Google Earth imagery

\section{Introduction}

Seagrass beds are important ecosystems in coastal areas. Marine organisms use this habitat as shelter and nursery ground as well as for foraging and spawning. Seagrass contribute to the ecosystem functions and biodiversity in shallow water areas (Hemminga and Duarte [1]). Seagrass beds can be composed of one or more species growing together on a single substrate that is within reach of sunlight.

In order to manage a seagrass ecosystem, is important to obtain detailed information on seagrass diversity and abundance. Insufficiently detailed information could end up leading to mismanagement of the area.

Remote sensing can be used to obtain information about the condition of seagrass beds in shallow coastal ecosystems with clear water, due to good light penetration and easily accessible field data (Green et al. [2]). Moreover, in some situations remote sensing has been shown to be more costeffective than field survey data collection and should be considered as an integral approach along with field data for monitoring seagrass communities. Mapping seagrasses via remote sensing can produce a more spatially comprehensive and inclusive representation of spatial distribution than point or transect based surveys (Lyons et al. [3]). Detailed mapping of seagrass condition requires remote sensing images with high spatial resolution, such as IKONOS, Quickbird, GeoEye-1 and WorldView-2.

The use of remote sensing imagery for mapping the seagrass condition has been carried out in Moreton Bay, Australia using Landsat 5-TM data (Roelfsema et al. [4]), and using a combination of Quickbird imagery and field data

\footnotetext{
- E-mail address: muhammadansharamran@gmail.com
}

ISSN: 1791-2377 @ 2017 Eastern Macedonia and Thrace Institute of Technology. All rights reserved.
(Lyons et al. [3]). Quickbird imagery has been used also to map seagrass condition in the waters around Barranglompo Island and Barrangcadddi Island, Makassar, Indonesia (Amran [5]). Wicaksono and Hafitz [6] used ALOS AVNIR2 and ASTER images to map leaf-area index (LAI) of seagrass in the Karimun Islands, Indonesia.

Google Earth was launched in 2005 as an internet-based computer service, which displays 3-4 year old satellite images of the entire surface of the earth with moderate resolution $(30 \mathrm{~m})$. Recently, Google Earth, supported by Digital Globe, has begun to display images with very high resolution that allow users to easily identify specific objects in natural or human built environments (Farah and Algarni [7]). Maps generated from Google Earth imagery have a high accuracy (Collin et al. [8]). Google Earth has many tools that allow users to obtain spatial data and even to add specific information to the image displayed, such as special notes and photographs (Potere [9], Farah and Algarni [7]).

Google Earth images can be downloaded for free as an image file. Displayed images have passed through several treatment processes, such as contrast stretching and sharpening. Even though the images provide by Google Earth are in natural colour, they can be decomposed into their colour components of red, green and blue (RGB).

In a clear water, substrate types such as sand, coral reefs, and seagrass beds are well portrayed on Google Earth images. West [10] used Google Earth images to detect the impact of boat activity on the seagrass Possidonia in Australia, while Collin et al. [8] used Google Earth imagery to map the seafloor substrate typology in Shiraho, Ishigaki Island of Japan, and generated maps with $89.7 \%$ accuracy using a maximum likelihood classification method.

The high resolution imagery in Google Earth offers opportunities for development in the methods used to map seagrass condition. With the goal of serving as many people 
as possible involved in coastal resources management, an easy-to-implement and transparent method should be built so that any person equipped with a computer, and internet access could make a detailed map of seagrass condition. This study aims to assess the reliability of Google Earth imagery as direct source of data for the mapping of seagrass condition.

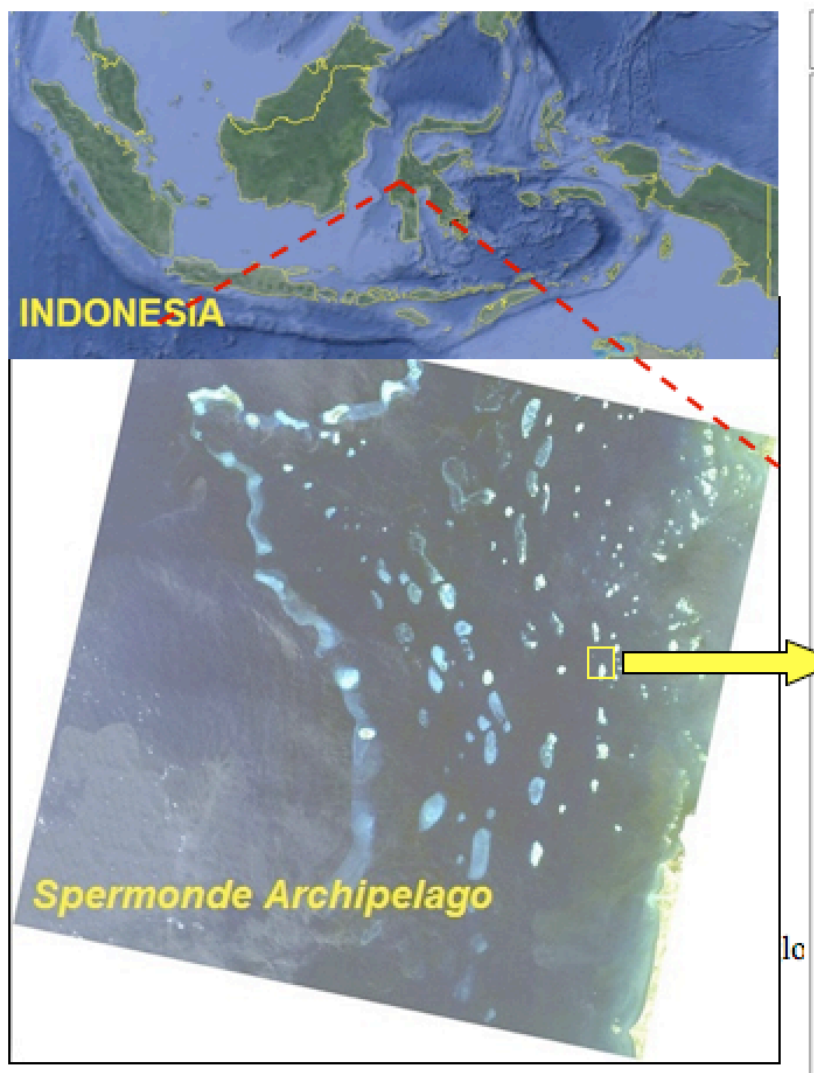

Fig. 1. Barranglompo Island study site

The Google Earth image used in this study was a natural colour image (RGB). The acquisition date could be specified using the historical imagery button included in the Google Earth toolbar (Fig. 2). Embedded at the bottom of the image is the company name of the source sensor (here, DigitalGlobe) following "Image (c) year". DigitalGlobe provides high resolution multispectral satellite images (IKONOS, QuickBird, GeoEye-1, WorldView-2 and WorldView-3).

A field survey was conducted to identify the species, referring to Waycott et al. [11], as well as taking photographs (Nikon camera, type Coolpix S32) of the seagrasses that were observed in the transects. The coordinates of quadrats were also recorded (Garmin GPSmap 76CSx). Seagrass species identification was based on the shape of leaves, rhizomes, flowers and fruit. The data collected from the field survey were divided into two independent clusters: the training cluster, which was used to define the class-specific pixel signatures required for classification, and the validation cluster, which was used to assess the accuracy of the image classification result.

\section{Materials and Methods}

This study combined image processing and field survey. The study area comprised the seas around Barranglompo Island (ca. $15 \mathrm{~km}$ from the mainland of Makassar), which is one of the small islands in the Spermonde archipelago (Fig. 1). Seagrass beds spread out extensively across the gently sloping intertidal and reef flat area at depths of $0.5-1.5$ meters. Various seagrass cover categories were observed in this area.

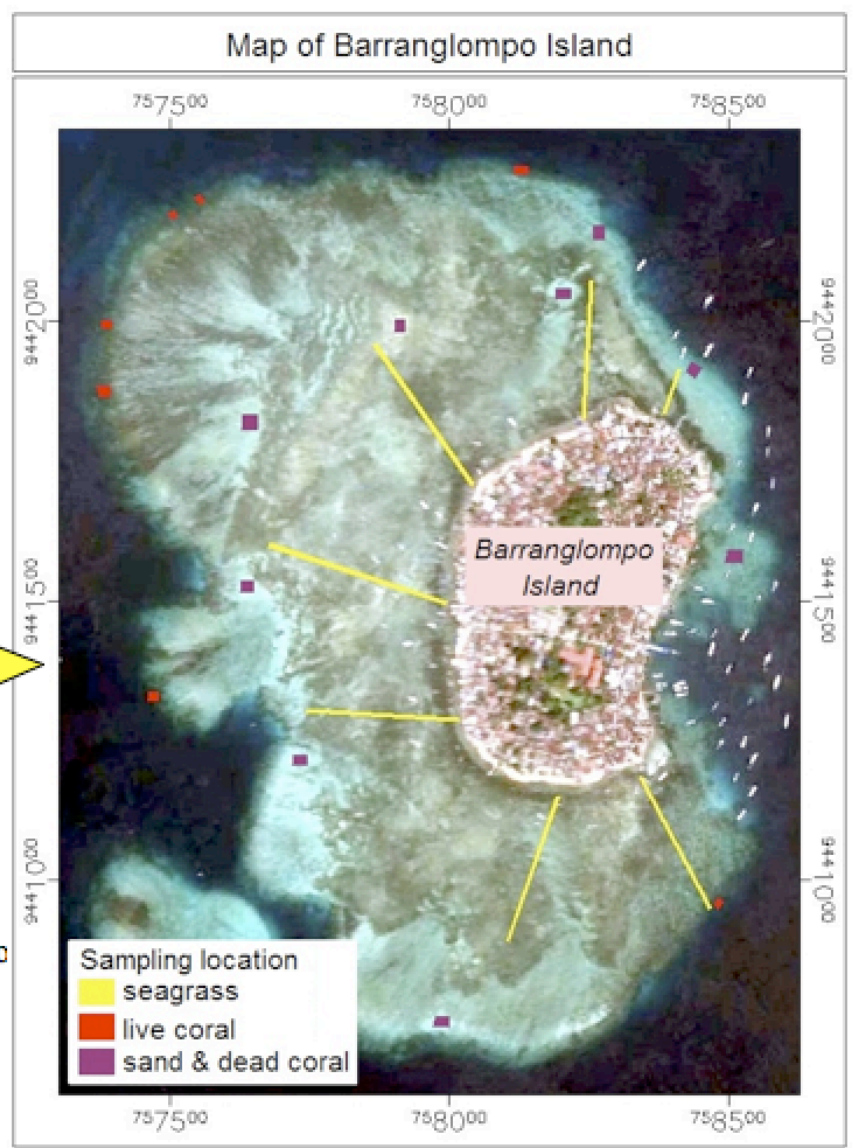

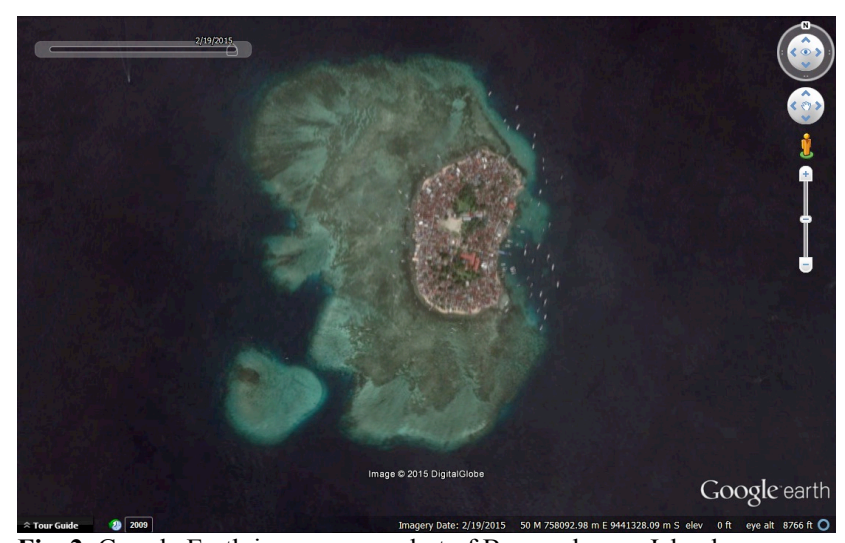

Fig. 2. Google Earth image screenshot of Barranglompo Island

\subsection{Station location}

Ground truthing stations were selected based on the seagrass percentage cover that was detected from the Google Earth image, which displayed different colours, hues and patterns. At each station, a transect line was set perpendicular to the 
coast, starting from the landward margin of the area where seagrasses were present to a point on the reef-slope (Fig. 1). Measurement points along the transect line were in the form of quadrats $(0.5 \mathrm{~m} \times 0.5 \mathrm{~m})$. Distance between quadrats was \pm 20 meters. Each quadrat was placed in a position representing homogeneous seagrass cover within a radius of 3 meters so that each plot could represent at least 4 pixels in the high resolution image.

\subsection{Determination of seagrass percentage cover and condition}

The seagrass percentage cover was measured by classifying quadrat photos using image processing software (ENVI 5.1) with maximum likelihood method. The objects within each quadrat were classified into seagrass and substrate (e.g. Fig. 3 ). Seagrass percentage cover was defined as the proportion of substrate covered by seagrass vegetation within a unit area when observed perpendicularly from above (Brower et al. [12]). Seagrass percentage cover (C), was calculated as:

$$
C=\frac{\alpha}{A} \times 100 \%
$$

Where $a$ is an area covered by seagrass in quadrat, and $A$ is a quadrat area. Seagrass condition was determined based on the criterion of seagrass percentage cover as shown in Tab. 1.

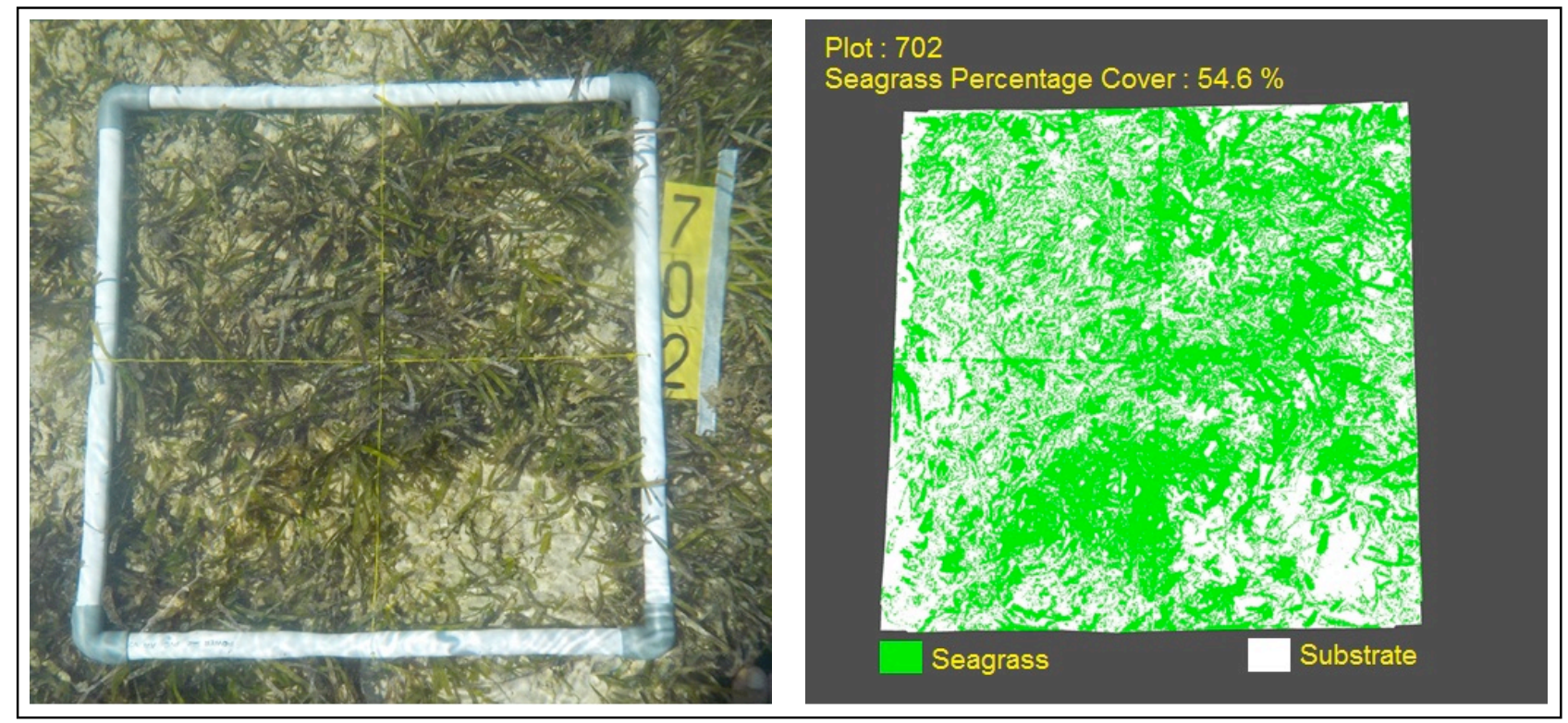

Fig. 3. Photograph and classified image of plot 702 (station 7, plot 02)

Table 1. Seagrass condition criterion based on seagrass percentage cover

\begin{tabular}{rc}
\hline Coverage & Assigned Condition \\
\hline$>75 \%$ & Very good \\
$50-75 \%$ & Good \\
$25-50 \%$ & Moderate \\
$<25 \%$ & Poor \\
\hline
\end{tabular}

\subsection{Image processing}

The image downloaded from Google Earth was a picture file in JPEG format without geographical coordinates, so that registration was necessary to produce a georeferenced image. The method used for image registration was first degree polynomial warping with nearest neighbour resampling based on ground control points (GCP) (Richards [13]).

Image masking was done to cover the land and boats in the image, so that the image processing was limited to areas where the substrate was underwater. This step was done by creating a binary image, giving a value of 1 to pixels under water, while land and boat pixels were given the value of 0 . The binary image was applied to the Google Earth image so that the pixel value of land and boats were not processed in subsequent image processing.

Image classification was done using the maximum likelihood method to obtain a map indicating the different substrate types present. Training areas were used, comprised of pixels that corresponded to the field samples. The resulting classes were seagrass beds, live coral, sand and dead coral, and deep sea. The seagrass class was subdivided to represent seagrass condition based on seagrass percentage cover in accordance with the criteria in Tab. 1. Sand and dead coral were combined into one class because they could not be distinguished in the image classification. The deep sea class comprised seafloor too deep to be detected by the satellite sensors.

Image classification was done based on the red, green and blue colour components of the Google Earth image. The classification process began by creating training areas, collecting pixel values for each colour component by substrate class. The sets of pixel values obtained were used as reference sets to group the pixels into classes. The maximum likelihood classification method requires statistical information such as the average value of each training area, standard deviation, variance and covariance. Such statistical information was automatically generated when creating the training area data sets. Based on this statistical information, the probability of each pixel to fit into a particular class could be calculated

\subsection{Accuracy assessment}

An error matrix was used to perform an accuracy assessment. Error matrices can test the conformity between ground truthing data and the results of image classification. Overall accuracy of the classification map is the proportion of the total correct pixels divided by the total number of pixels in the error matrix (Jensen [14], Richards [13]). In 
addition, the value of the Kappa Coefficient was also calculated. The Kappa Coefficient is a measure of classifier performance derived from the error matrix (Tab. 2). The Kappa Coefficient (k) was calculated as:

$$
k=\frac{N \sum_{i=1}^{k} x_{i i}-\sum_{i=1}^{k}\left(x_{i+} * x_{+i}\right)}{N^{2}-\sum_{i=1}^{k}\left(x_{i+} * x_{+i}\right)}
$$

where:

$$
\begin{aligned}
& N: \text { total number of pixels } \\
& x_{i i}: \text { number of correctly classified pixels } \\
& x_{i+} \text { : number of marginal pixels in the row } i \text { (thematic } \\
& \text { map classes) } \\
& x_{+i} \text { : number of marginal pixels in the column } i \\
& \text { (reference data classes) } \\
& k \text { : total number of classes }
\end{aligned}
$$

Table 2. Suggested ranges for the Kappa Coefficient (Richards, 2013)

\begin{tabular}{cc}
\hline $\mathbf{k}$ & Classification can be regarded as \\
\hline$<0.4$ & Poor \\
$0.41-0.60$ & Moderate \\
$0.61-0.75$ & Good \\
$0.76-0.80$ & Excellent \\
$>0.81$ & Almost perfect \\
\hline
\end{tabular}

\section{Results}

The natural colour image downloaded from Google Earth had an acquisition date of February 19, 2015. Based on the DigitalGlobe website (http://browse.digitalglobe.com/imagefinder) the image was a GeoEye1 image with $1.65 \mathrm{~m}^{2}$ resolution. Registration of the image was performed based on 10 GCP with RMSerror $=0.37$. Georeferencing was performed using UTM coordinates, in zone $50 \mathrm{M}$ and using the 1984 World Geodetic System (WGS84) datum.

Field surveys were conducted on 6 to 8 July 2015 to identify the seagrass species and photograph the quadrats. There were no natural phenomena or human activity that was considered likely to result in significant changes in seagrass condition during the time interval between image acquisition and field measurements; hence it was assumed that the image represented the seagrass condition as measured in the field. Each seagrass condition class (Tab. 1) was represented by 104 field samples (quadrats), consisting of 44 plots in the training cluster and 60 plots in the validation cluster (Tab. 3 ).

Table 3. Field samples (quadrats)

\begin{tabular}{lcc}
\hline \multicolumn{1}{c}{ Class } & Training cluster & Validation cluster \\
\hline Seagrass & 30 & 40 \\
Live coral & 7 & 10 \\
$\begin{array}{l}\text { Sand and dead } \\
\text { coral }\end{array}$ & 7 & 10 \\
\hline \multicolumn{1}{c}{ Total } & 44 & 60 \\
\hline
\end{tabular}

There were eight species found in the study area: Cymodocea rotundata, Cymodocea serrulata, Enhalus acoroides, Halodule pinifolia, Halodule uninervis,
Halophila ovalis, Syringodium isoetifolium and Thalassia hempricii. The dominant species with the highest coverage was Enhalus acoroides. Generally, these seagrass species formed mixed species meadows with two or more species. Species composition varied between locations (quadrats).

Sea waters quality and seabed substrate were suitable for promoting the establishment and growth of seagrasses. The seawater was very clear so that sunlight needed for photosynthesis could penetrate to the seafloor. The substrate consisted of sand and coral fragments with sizes varying from fine sand to granules.

Image classification results identified seagrass beds on the reef flat around Barranglompo Island, located to the north, west and south of the island (Fig. 4). Seagrass vegetation within the study site formed extensive meadows spreading out over the tidal flats. Seagrass condition varied but was mostly in moderate and good condition categories. Average pixel values of the three colour components (red, green and blue) for each class are presented in Fig. 5. Fig. 6 shows the proportional area in each class based on seagrass condition. Compared to previous studies, the results indicated that seagrass percentage cover had increased. Amran [5] reported that the percentage of seagrass cover in the seas around Barranglompo Island in 2008 was mostly less than $50 \%$, in the poor or moderate condition categories.

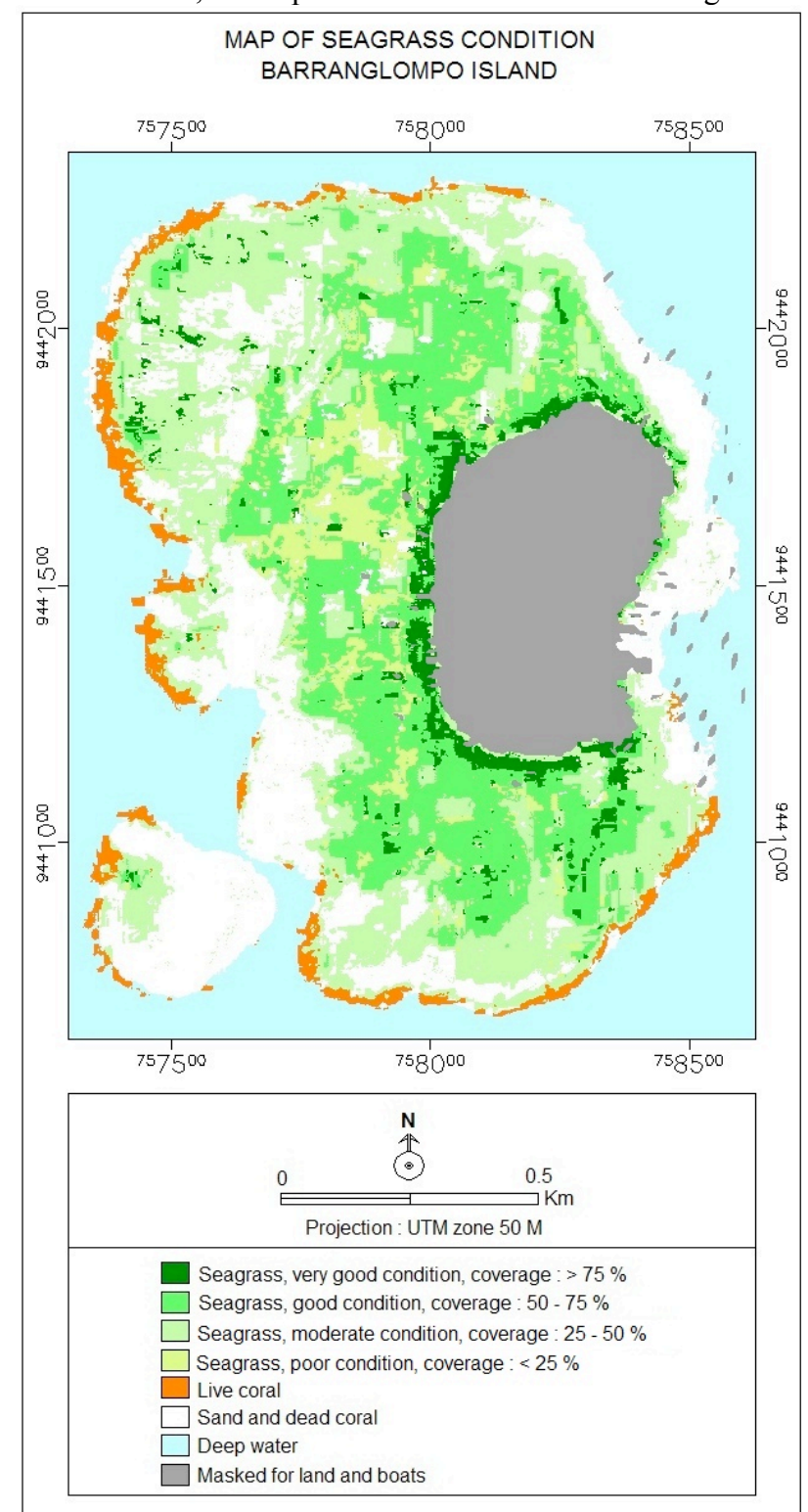

Fig. 4. Map of seagrass condition of Barranglompo Island 


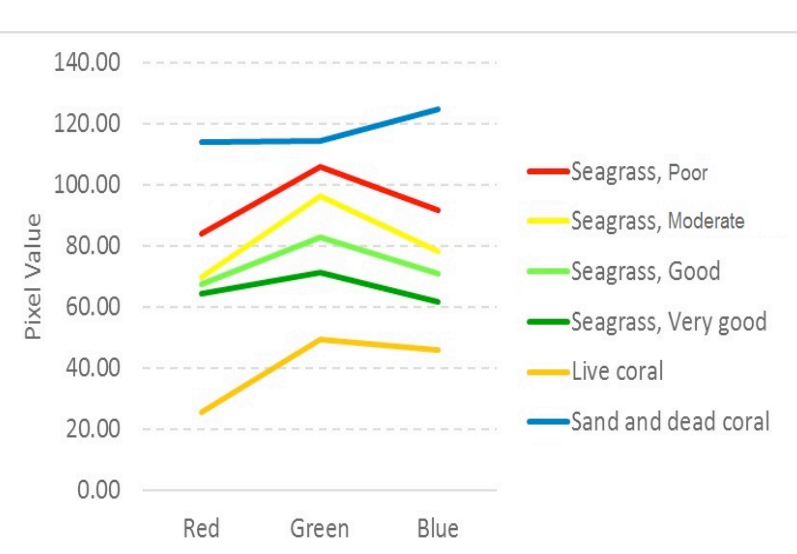

Fig. 5. Average pixel values in each class

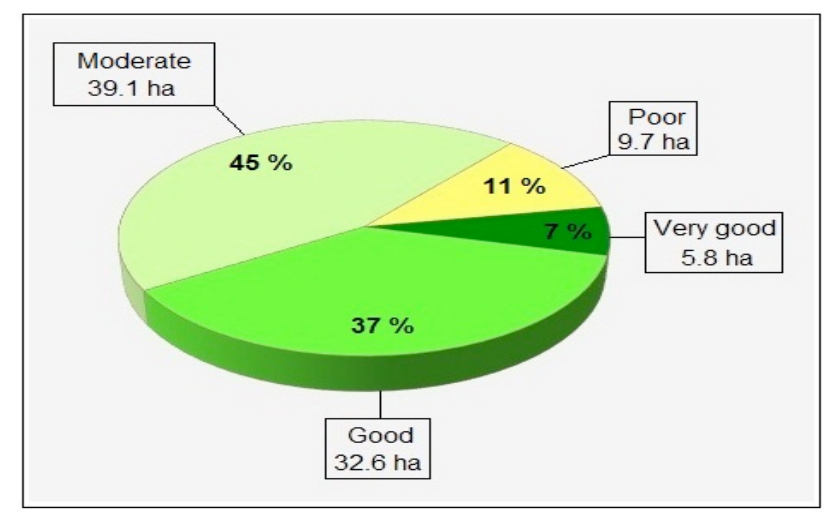

Fig. 6. Proportion of area covered based on seagrass condition

The classification accuracy assessment showed that overall accuracy reached a quite high value of $85.7 \%$, while the producer's accuracy and user's accuracy for each class exceeded $70 \%$ (Tab. 4). The Kappa Coefficient was 0.83 , which means that the classification result could be regarded as almost perfect.

Table 4. Accuracy assessment

\begin{tabular}{|c|c|c|c|c|c|c|c|c|c|}
\hline & & \multicolumn{7}{|c|}{ Number of pixels of referenced data } & \multirow{2}{*}{$\begin{array}{c}\text { User's } \\
\text { accuracy }\end{array}$} \\
\hline & & VGS & GS & MS & PS & $\mathbf{L C}$ & SDC & SR & \\
\hline \multirow{7}{*}{ 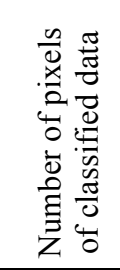 } & VGS & 36 & 0 & 4 & 0 & 0 & 0 & 40 & 90.0 \\
\hline & GS & 5 & 41 & 0 & 0 & 0 & 0 & 46 & 89.1 \\
\hline & MS & 0 & 0 & 35 & 6 & 0 & 0 & 41 & 85.4 \\
\hline & PS & 0 & 0 & 0 & 32 & 0 & 5 & 37 & 86.5 \\
\hline & $\mathrm{LC}$ & 0 & 0 & 0 & 0 & 34 & 6 & 40 & 85.0 \\
\hline & SDC & 0 & 0 & 0 & 5 & 4 & 32 & 41 & 78.0 \\
\hline & $\mathrm{SC}$ & 41 & 41 & 39 & 43 & 38 & 43 & & \\
\hline \multicolumn{2}{|c|}{ Producer's accuracy } & 87.8 & 100 & 89.7 & 74.4 & 89.5 & 74.4 & & \\
\hline \multicolumn{10}{|c|}{ Overall accuracy $=85.7 \%$} \\
\hline \multicolumn{10}{|c|}{ Kappa Coefficient $=0.83$} \\
\hline \multicolumn{5}{|c|}{ VGS: very good seagrass class. } & \multicolumn{4}{|c|}{ LC: live coral class } & \\
\hline \multicolumn{5}{|c|}{ GS: good seagrass class } & \multicolumn{4}{|c|}{ SDC: sand and dead coral class } & \\
\hline \multicolumn{5}{|c|}{ MS: moderate seagrass class } & \multicolumn{4}{|c|}{ SR: sum of pixels in the row } & \\
\hline \multicolumn{5}{|c|}{ PS: poor seagrass class } & \multicolumn{4}{|c|}{ SC: sum of pixels in the column } & \\
\hline
\end{tabular}

\section{Discussion}

Seagrass species variation in the waters around Barranglompo Island was high, with 8 species, similar to the seagrass diversity reported by Supriadi et al. [15]. Seagrass species grow in a variety of combinations at this site. This means that the image pixel values, as a representation of the reflected energy received by the sensor, did not represent a particular species of seagrass.

When light penetrates water, its intensity decreases with increasing depth. The severity of attenuation differs with the wavelength of electromagnetic radiation. The spectral radiances recorded by a sensor are therefore dependent on the reflectance of substrate, optical properties and depth of water (Green et al. [2]). Ideally, the image should be corrected to account for the water column depth, but in this study it was not done. The Google Earth image was downloaded in JPEG format and had undergone contrast stretching and sharpening so that the pixel value could not be calibrated to the radiance needed for water column correction. In addition, seagrasses in the study site grow in very clear waters with a relatively similar depth so that the influence of the water column could be considered relatively uniform.
Average pixel values for each of the colour components in the seagrass classes differed from those in sand and dead coral class and live coral class (Fig. 5). The sand and dead coral class had the highest average pixel values in all colour components, while the live coral class had the lowest value. This was in line with the results of spectral reflectance measurements of seagrass and sand by Maffione [16] using a spectrometer. The spectral reflectance curve of seagrass and sand indicates that these substrate types can be significantly differentiated, and sand reflectance is always higher than that of seagrass in the visible light spectrum $(400-700 \mathrm{~nm}$ wavelengths). Statistically, the Google Earth image had the potential to be classified based on seagrass condition, referring to the differences in pixel value for each class. The classification accuracy assessment showed good values for overall accuracy and the Kappa Coefficient.

The peak pixel values for seagrass classes were in the green component. This was similar to the research by Han [17] and Thorhaug et al. [18] who found that the peak of seagrass spectral reflectance was at $560 \mathrm{~nm}$ wavelength which is included in the green spectrum. The spectral reflectance peak was influenced by chlorophyll in seagrass leaves. Chlorophyll reflects electromagnetic radiation in the green spectrum but absorbs light at wavelengths in the blue and red spectra. 
The pixel values for the various classes of seagrass formed a similar pattern but that the value decreased when the seagrass percentage cover increased (Fig. 5). Pixel value represents the combined effects of exposed substrate and seagrass cover. Seabed radiance comes from the combined reflection of the abiotic substrate and other objects that grow or lie on the seafloor. According to the spectral reflectance characteristics, substrate reflectance gives a greater contribution to seabed radiation compared to other objects on the seafloor. Maffione [16]) showed that seagrass reflectance is $3-4$ times smaller than that of sand, so the presence of seagrass will cover the substrate and denser seagrass coverage would reduce seabed radiance further.

Google Earth provides serial image data by month and year, so the mapping method used in this study could be applied for monitoring seagrass, for example, detection of changes in condition or extent. In addition, this mapping method is not expensive because the Google Earth image can be downloaded for free.

\section{Conclusion}

This study has shown that Google Earth imagery can provide a reliable direct source of data for mapping of seagrass condition with a good accuracy. The resulting map can illustrate detailed information because it comes from a highresolution image.

This is an Open Access article distributed under the terms of the Creative Commons Attribution Licence

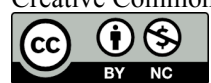

\section{References}

1. M.A.Hemminga and C.M. Duarte, Seagrasses Ecology, Cambridge University Press, Cambridge, p. $248-251$ (2000).

2. E.P. Green, P.J. Mumby, A.J. Edward, and C.D. Clark, Remote Sensing Handbook for Tropical Coastal Management, UNESCO, Paris, p. $175-180$ (2000).

3. M. Lyons, S. Phinn, and C.M. Roelfsema, Remote Sensing. 3, 42 (2011).

4. C.M. Roelfsema, S.R. Phinn, N. Udy, and P. Maxwell, Spatial Science. 54-1, 45 (2009).

5. M.A. Amran, BIOTROPIA: The Southeast Asian Journal of Tropical Biology. 17-1, 42 (2010)

6. P. Wicaksono, and M. Hafitz, European Journal of Remote Sensing. 46, 18 (2013)

7. A. Farah, and D. Algarni, Artificial Satellites. 49-2, 101 (2014).

8. A. Collin, K. Nadaoka, and T. Nakamura, ISPRS International Journal of Geo-Information. 3, 1157 (2014).

9. D. Potere, Sensor. 8, 7973 (2008).

10. J.R. West, WETLANDS (Australia). 26-2, 3 (2011).
11. M. Waycott, K. McMahon, J. Mellos, A. Calladine, and D. Kleine, A Guide to Tropical Seagrasses of the Indo-West Pacific, James Cook University, Townsville, p. 18 - 67 (2004).

12. J.E. Brower, J.H. Zar, and C.N. von Ende, Field and Laboratory Methods for General Ecology, Wm.C. Brown Publisher, Dubuque, p.78 (1990).

13. J.A. Richards, Remote Sensing Digital Image Analysis, An Introduction, Springer-Verlag, New York, p. $56-65$ and 396-405 (2013).

14. J.R. Jensen, Introductory Digital Image Processing: A Remote Sensing Perspective, Pearson Prentice Hall, Upper Saddle River, p. $495-513$ (2005).

15. Supriadi, R.F. Kaswadji, D.G. Bengen, and M. Hutomo, Ilmu Kelautan, 19-1, 1 (2014).

16. R.A. Maffione, Backscatter, Summer, 28 (2000).

17. L. Han, Photogrammetric Engineering \& Remote Sensing, 67, 99 (2001).

18. A. Thorhaug, A.D. Richardson, and G.P. Berlyn, International Journal of Remote Sensing, 28-7, 1487 (2007). 